\title{
Amending the revisionist model of the Capgras delusion: A further argument for the role of patient experience in delusional belief formation
}

\author{
Garry Young \\ The Psychology Division \\ Nottingham Trent University \\ garry.young[]ntu.ac.uk \\ Received May 2014; accepted December 2014; published winter 2014/2015.
}

\begin{abstract}
Recent papers on the Capgras delusion have focused on the role played by subpersonal abductive inference in the formation and maintenance of the delusional belief. In these accounts, the delusional belief is posited as the first delusion-related event of which the patient is conscious. As a consequence, an explanatory role for anomalous patient experience is denied. The aim of this paper is to challenge this revisionist position and to integrate subpersonal inference within a model of the Capgras delusion which includes a role for experiential content. I argue that the following revisionist claims are problematic: (a) that a fully-formed belief enters consciousness, and (b) that this is the first conscious delusion-related event. Instead, it is my contention that a delusional thought (arrived at through subpersonal abductive inference) and an anomalous experience co-occur in consciousness prior to the formation of the delusional belief. The co-occurrence of thought and anomalous experience overcomes problems with the revisionist position resulting in an account of the Capgras delusion with greater explanatory efficacy.
\end{abstract}

Keywords: Bayes' theorem; Abductive inference; Anomalous experience; Endorsement and explanationist accounts; Indicative imagination; Face recognition system; Skin conductance response (SCR). 


\section{Introduction}

Patients suffering from the Capgras delusion typically believe that at least one family member or friend-some significant other-is an impostor (Capgras \& Reboul-Lachaux 1923). The 'impostor' is acknowledged by the patient to be a close physical match to the putatively genuine other who is always absent. ${ }^{7}$ When considering the Capgras delusion, contemporary accounts typically seek to address the following inter-related questions (or certainly are required to answer these): (i) What causes this particular delusional belief? (ii) Why is the belief accepted? (iii) Why is it maintained?

With regard to (i), theorists look to explain the belief's specific content; that is, what causes the patient to believe this in particular (say, in the case of the Capgras husband, that his wife is an impostor). In the case of (ii), what needs to be clarified is why and how the proposition "This woman is not my wife, she is an impostor" becomes something that the patient believes rather than merely entertains and then dismisses. Finally, even after forming the belief, it needs to be explained why the patient is so resistant to revising it, especially given the often overwhelming evidence available to contradict the delusional content.

Addressing question (iii) is not a concern of this paper, and will be touched on only briefly in Section 6. Of interest are questions (i) and (ii). The first concerns characteristics of the delusional content; the second with the epistemic status of the delusion: that it is a belief. The focus of this paper is therefore on factors that contribute to the formation of the delusional belief with specific monothematic 'imposter' content. In addition, while acknowledging the neuropsychological disruption underlying the disorder, as well as recent discussion on subpersonal abductive reasoning, I wish to emphasize the role played by patient experience-often referred to as 'anomalous' in the literature-in the explanatory account proffered here. It is my view that the co-occurrence of anomalous experience and delusional belief creates an interaction of mutual effect, such that the former validates the latter and the latter authenticates the former (Young 2008a, 2011a, 2011b). The result of which is an entrenched delusional state. The account I propose here also has features that are compatible with explanationist and endorsement approaches to the Capgras delusion.

\footnotetext{
${ }^{7}$ Young (1999) notes that there have been reports of Capgras patients who claim to perceive differences in the 'impostor' but when pressed on what exactly these differences are often have difficulty pointing them out. See Frazer and Roberts (1994), however, for an example of where this is not the case and specific differences are articulated.
} 


\subsection{A bit of background information}

One way to understand why the belief is formed is to consider what function it serves. On this issue, contemporary accounts tend to fall into two camps: those that favour an explanationist approach and those that favour an endorsement approach (Pacherie 2009). Until recently, each approach assumed that an anomalous (conscious) experience occurred prior to the formation of the delusional belief. The nature of this experiential content is such that the belief either endorses the experience-that is, the experience contains 'impostor wife' content such that one believes what one sees (much like seeing a tree in front of you causes you to believe there is a tree in front of you) - or the belief is positioned so as to explain the anomalous nature of the experience. That is, the (delusional) belief is selected as the best candidate for the job. The experience is itself said to be the result of some form of neurological disruption (Ellis \& Young 1990). Depending on which approach one favours, the delusional belief functions either to explain the anomalous experience or to endorse its content. The first stage of either approach can therefore be broken down into the following components: neurological deficit, anomalous (conscious) experience, delusional belief (see figure 1).

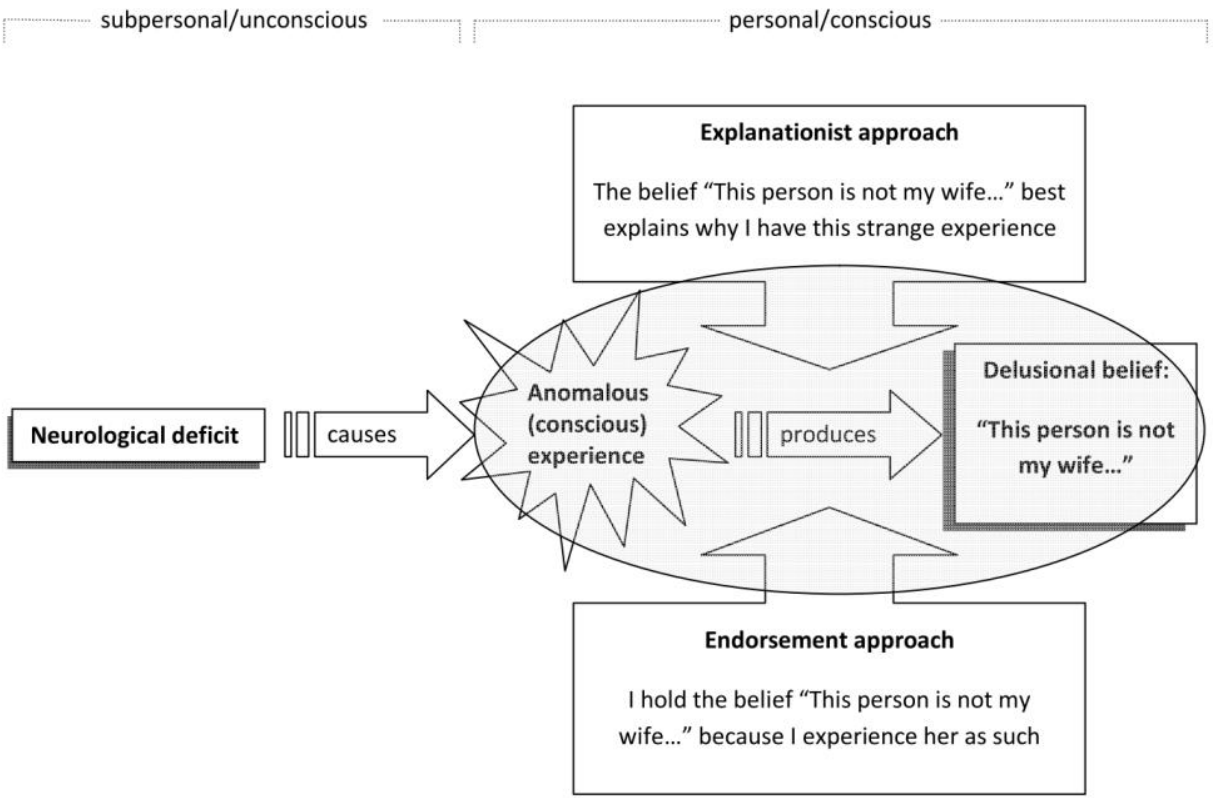

Figure 1: Shows the different components within stage 1 of a traditional explanation of the Capgras delusion, and how the explanationist and endorsements approaches differ in terms of the relationship between anomalous experience and delusional belief. 
In their 2010 paper, Abductive inference and delusional belief, Max Coltheart and colleagues (Coltheart, Menzies \& Sutton) present a revised account of the Capgras delusion in which they argue-using the example of a Capgras husband in the presence of his wife-that (1) the emergence into consciousness of the belief "This is not my wife, she is an impostor" is the product of a Bayesian-style abductive inference (one revision), (2) that the process described in (1) occurs completely at the subpersonal level (that is, below the level of conscious awareness; another revision), and (3) that, as a consequence of (1) and (2), there is no longer a need for anomalous phenomenal content to play an explanatory role in the aetiology of the delusional state (a further revision that contrasts sharply with figure 1). An abductive inference is posited as a means of selecting the best hypothesis from those available to explain a discrepancy within the patient's face recognition system (see Breen, Caine \& Coltheart 2000; and Ellis \& Lewis 2001; Ellis \& Young 1990); a discrepancy identified by the patient subpersonally, which Coltheart et al. refer to as abnormal data $\mathrm{O}$. At best, any anomalous experience is seen merely as a consequence not a cause of the belief.

Coltheart et al.'s model is explanationist because the process of Bayesian-style abductive inference is used to select the best hypothesis from those available to explain abnormal data $\mathrm{O}$. It differs from traditional explanationist accounts, however, insofar as what needs to be explained is not something the patient is conscious of. Coltheart et al.'s model therefore posits the following procedure: neurological deficit causes abnormal data O, Bayesian-style abductive inference to the best explanation selects the hypothesis "This person is not my wife...", the delusional belief-“This person is not my wife..."-enters consciousness (see figure 2). 

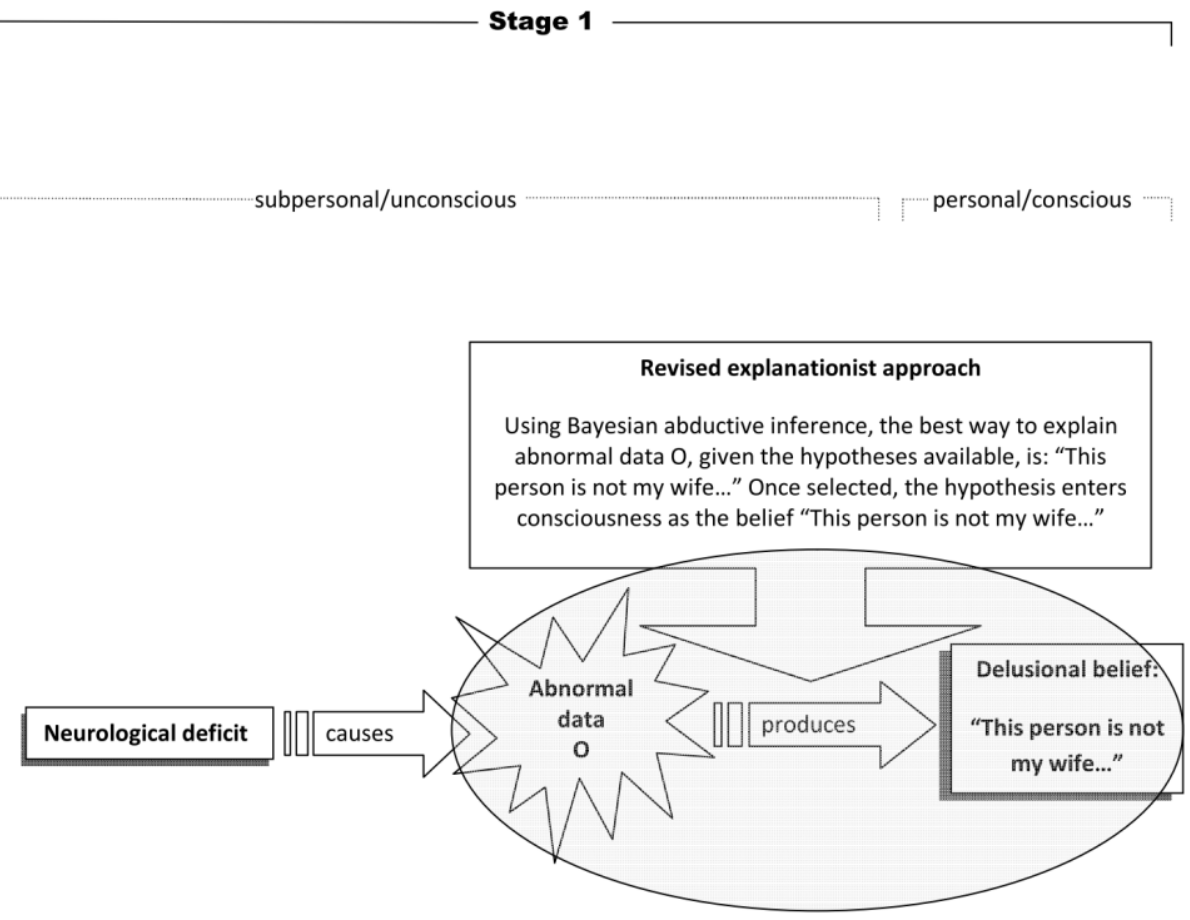

Figure 2: Shows the different components within stage 1 of the explanatory model proposed by Coltheart et al. While still an explanationist approach, within this model the delusional belief is no longer posited to explain the anomalous (conscious) experience; rather the belief is said to be the product of Bayesian-style abductive inference which selects the best hypothesis to explain (at the subpersonal level) abnormal data $\mathrm{O}$.

\subsection{Aims}

For a number of years now, I have argued that patient experience is an important feature of any explanation of the Capgras delusion. I have also argued that a clearer way of conceiving of this 'anomalous' experience is required (see Young 2007, 2008b, 2009, 2010). In light of Coltheart et al.'s revisionist model, which removes the traditional role of anomalous experience from the explanation, the aim of this paper is to reinstate this role. Specifically, I intend to proffer a role for anomalous patient experience within stage 1 of an explanatory account of the Capgras delusion (that is, to the formation of the delusional belief). To support the case for the explanatory relevance of patient experience, I will (i) highlight the problems with Coltheart et al.'s revisionist model, (ii) show how these problems can be resolved by reinstating a role for anomalous patient experience, and (iii) present an account of stage 1 which does not require that Coltheart et al.'s revisionist approach be abandoned altogether. Instead, the revisionist approach merely needs to endorse the cooccurrence of an impostor thought (which is transformed into an impostor 
belief after entering consciousness) and patient experience, which is itself transformed from an initial salient sense of unfamiliarity (or estrangement) into a normative (when in the presence of a stranger) lack of familiarity. The co-occurrence of belief and experience become congruent and mutually verifying. The experiential state gives credence to the freshly emerged impostor thought such that the corresponding (delusional) belief is formed to explain the experience. For its part, the belief then helps shape the experience, and an 'impostor' is duly perceived. After that, the belief continues simultaneously to shape and endorse the patient's experience, not only in terms of seeing an impostor but also in terms of the normative lack of familiarity that accompanies this perception.

Before discussing any of this in detail, however, I begin with an overview of Coltheart et al.'s model, including an analysis of what makes 'abnormal data O' abnormal, such that it should be best explained by what is sometimes referred to in the literature as the stranger hypothesis.

\section{Coltheart et al.'s model}

\subsection{The neurocognitive basis for abnormal data $O$}

As part of their revised model of delusions, Coltheart et al. endorse the work of William James (James 1890/1950) and Brendan Maher (Maher 1974). Coltheart et al. agree with these authors that the delusional belief is essentially a means of explaining the patient's unusual bodily sensations (James) or anomalous perceptions (Maher). An explanatory model of this kind is by no means new, of course (see Bayne \& Pacherie 2004; Bortolotti 2005; Davies \& Coltheart 2000; Ellis \& Young 1990; Gilleen \& David 2005; Klee 2004; Stone \& Young 1997; Young \& de Pauw 2002). These earlier accounts, however, tended to state or otherwise imply that the anomalous sensation or perceptionwhich the delusional belief is used to explain-is something the patient is conscious of: it forms part of the phenomenal quality of their (conscious) experience. In contrast, what is revisionist about Coltheart et al.'s model (as noted above) is that the explanandum - the sensation or perception in need of explanation-is identified subpersonally. As Coltheart et al. state:

[T]he first delusion-relevant event of which the patient is aware is the belief “That isn't my wife”. Everything that preceded the occurrence of that belief and was responsible for the belief having come about-the stroke, the neuropsychological disconnection, the absence of an autonomic response when the wife is next seen, the invocation of a process of abductive inference to yield some hypothesis to explain this, and the successful generation of such a hypothesis-all of these processes are unconscious. What's conscious is only the outcome that this chain of processes generated: the conscious belief “This person isn't my wife”. (2010: 264; emphasis added) 
One part of Coltheart et al.'s account which does remain consistent with the position adopted by these other theorists, however, is the claim that the origins of the Capgras delusion can be traced to a disruption in the patient's normal neuropsychological functioning. Again, in the words of Coltheart et al.:

What could possibly suggest to someone the idea that the woman he is looking at (who is in fact his wife) is not his wife but some complete stranger? We believe the answer to this question is: a neuropsychological impairment that has disconnected the face recognition system (itself intact) from the autonomic nervous system (itself intact). (2010: 262)

Although not stated explicitly in the 2010 paper (although see Davies, Coltheart, Langdon \& Breen 2001), Coltheart et al. seem to be following Ellis and Lewis's (2001) explanatory approach to the Capgras delusion. Thus, after normal processing by the face recognition unit (FRU; located within the fusiform gyrus; see Schweinberger \& Burton, 2003, for details), there occurs a mismatch between information processed by the component of the face recognition system believed to be responsible for the identification of a person's face-the person identity nodes (PINs; located in the anterior temporal region)-and that responsible for the subject's normal autonomic response to a familiar person: the affective response to familiar stimuli component believed to be subserved by the ventral limbic structure projecting to the amygdala (see Breen et al. 2000, for a more detailed discussion on this, and also Haxby, Hoffman \& Gobbini 2000; Haxby, Gobbini, Furey, Ishai, Schouten, et al. 2001). ${ }^{8}$ This can be seen when Coltheart et al. state that the patient's wife "has been replaced by someone else, someone whom [the husband considers to be] a stranger even while acknowledging that this person does look very like [his] wife" (2010: 262). In the case of the Capgras husband, the PINs component is said to be intact enabling him to recognize (physically) the person in front of him, but the autonomic response is disrupted, as evidenced by the reduction in skin conductance response (SCR) (Brighetti, Bonifacci, Borlimi, Rosita \& Ottaviani 2007; Ellis, Young, Quayle \& de Pauw 1997; and Hirstein \& Ramachandran 1997). Together, this produces abnormal data O. Moreover, and again not explicitly stated by Coltheart et al., it is my contention that a likely location for the processing of O-based on Ellis \& Lewis' (2001) model of face recognition-is the Integrative device. This component is postulated by Ellis and Lewis to enable a comparison to be made between the expected autonomic response (based on a normative state; see below for discussion) and the

\footnotetext{
${ }^{8}$ Originally, conscious recognition was believed to involve the ventral route which projects from the primary visual cortex to the inferotemporal cortex (see Bauer 1984). Conversely, in the case of Capgras delusion, the underlying aetiology of delusional beliefs - the anomalous phenomenal experience - was believed to stem from damage to the dorsal route which projects, again, from the primary visual cortex, only this time to the posterior parietal cortex. Breen et al. (2000), however, suggest that covert recognition is subserved, not by the dorsal route (which they argue plays no part in visual recognition), but by pathways that connect the ventral stream to the limbic system (ventral limbic structure) and, in particular, the amygdala. (I shall adopt Breen et al.'s revision here.)
} 
actual response. As a result of this comparison, Ellis and Lewis further conjecture that some form of attribution takes places. Perhaps this attribution (of the cause of the discrepancy identified within the Integrative device) is arrived at through a process of Bayesian-style abductive inference, as Coltheart et al. maintain.

\subsection{Data $O$ as a deviation from the normative state}

In exploring this possibility further, for $\mathrm{O}$ to be identified as abnormal within the Capgras patient, there must occur a discrepancy between $O$ and some normative state of facial recognition $\left(\mathrm{O}_{\mathrm{n}}\right)$. As Coltheart et al. remark: "When you do encounter her, you will expect the usual consequences-a response by your autonomic nervous system. But this does not happen” (p.263; emphasis added). What might the discrepancy between the expected and the actual look like? Ceteris paribus, when in the presence of his wife, the following normative state should arise in the husband's face recognition system. Let us call this version of $\mathrm{O}$ the normative wife state $\left(\mathrm{O}_{\mathrm{nw}}\right)$.

$\left(\mathrm{O}_{\mathrm{nw}}\right)$ PINs activation occurs (signifying visual identification) in conjunction with heightened autonomic arousal (as measured by increased SCR).

When in the presence of a stranger, however, the normative state is captured by the following version of $\mathrm{O}$. Let us call this the normative stranger state $\left(\mathrm{O}_{\mathrm{ns}}\right)$.

$\left(\mathrm{O}_{\mathrm{ns}}\right)$ PINs inactivity (signifying no visual identification) is associated with low autonomic arousal (as measured by reduced SCR).

The abnormal state of $\mathrm{O}$ within the Capgras patient consists of PINs activity (signifying identification) and low autonomic arousal (associated with a stranger). Consequently, it matches neither normative state $\left(\mathrm{O}_{\mathrm{nw}}\right)$ nor $\left(\mathrm{O}_{\mathrm{ns}}\right)$, resulting in an error signal. From the perspective of the Capgras husband, then, given the state of $\mathrm{O}$ and its deviation from $\left(\mathrm{O}_{\mathrm{nw}}\right)$ and $\left(\mathrm{O}_{\mathrm{ns}}\right)$, how might he explain the abnormality: this error signal?

\subsection{The role of Bayesian-style abductive inference}

According to Coltheart et al., at the subpersonal level, two mutually exclusive hypotheses present themselves: the wife hypothesis $\left(\mathrm{H}_{\mathrm{w}}\right)$ and the stranger hypothesis $\left(\mathrm{H}_{\mathrm{s}}\right)$, respectively. 
$\left(\mathrm{H}_{\mathrm{w}}\right)$ This person who looks like my wife and claims to be my wife is my wife.

$\left(\mathrm{H}_{\mathrm{s}}\right)$ This person who looks like my wife and claims to be my wife is not my wife.

When considering each of these, the Bayesian approach adopted by Coltheart et al. entails calculating which hypothesis best explains $\mathrm{O}$ (the abnormal data). The calculation involves offsetting the prior probability (prior to observing 0 ) of each hypothesis being true against the explanatory power of the hypothesis (the ability of each to make sense of 0 ). Explanatory prowess is a function of how well $O$ is explained by the hypothesis, such that, given the truth of the hypothesis, it indicates the likelihood of $\mathrm{O}$ occurring. If a hypothesis explains $\mathrm{O}$ well, then the likelihood of it occurring given its truth will be high. As a means of demonstrating Bayes' theorem, Coltheart et al. present their own estimated probability ratios. The prior probability of $\left(\mathrm{H}_{\mathrm{s}}\right)$ they estimate at $1: 100$, whereas the prior probability of $\left(\mathrm{H}_{\mathrm{w}}\right)$ is given the much higher value of 99:100. When prior probability is considered in conjunction with the explanatory power of each to explain $\mathrm{O}$ (which includes the estimated likelihood of $\mathrm{O}$ occurring if a given hypothesis is correct), Coltheart et al. attempt to demonstrate (relative to each hypothesis available) that given a sufficiently high explanatory power, it is reasonable to select one hypothesis over the other as the most suitable. Thus, whilst the prior probability of the truth of $\left(\mathrm{H}_{\mathrm{s}}\right)-$ that the person is in fact a stranger even though she looks just like the patient's wife and claims to be her-may be low (estimated at 1:100), it is nevertheless claimed to have high explanatory prowess because it is more able to explain the abnormality evident in $\mathrm{O}$ than the wife hypothesis despite $\left(\mathrm{H}_{\mathrm{w}}\right)$ having an estimated higher prior probability of being true. Through the use of abductive inference, Coltheart et al. argue that the hypothesis corresponding to "This is not my wife..." is selected at the subpersonal level in manner consistent with normal reasoning by the Capgras husband.

\section{Challenges to Coltheart et al.'s model}

The claim that the selection of hypothesis $\left(\mathrm{H}_{\mathrm{S}}\right)$ is consistent with normal reasoning supports Maher's view (see Maher 1974, 1988, 1999; and also Gerrans 2002) that delusional beliefs are the product of a rational process. But as alluded to earlier, the fact that this putatively rational process occurs subpersonally and functions to explain abnormal data 0 , which the patient is not consciously aware of, is in contrast to the view expressed by Maher: that we should look to the nature and intensity of the phenomenal experience when trying to explain delusional beliefs. It also stands against Gerrans (2000) claim that what the patient is trying to explain is a "deeply disturbing and intractable phenomenal state” (p. 116). Coltheart et al. do not reject the role of patient 
experience altogether, however. In keeping with Maher and Gerrans, they accept that some delusional beliefs are likely to be a response to unusual patient experience; just not the Capgras delusion.

Criticism of Coltheart et al.'s model comes in two forms. First, whether the selection of hypothesis $\left(\mathrm{H}_{\mathrm{s}}\right)$ is the result of a rational process; that is, whether it shows evidence of a normative Bayesian model at work or, instead, some form of cognitive bias. Second, whether the delusional belief is the first delusion-related event of which the patient is conscious, or whether the patient is also conscious of an altered phenomenal state (an anomalous experience) prior to the formation of the belief.

\subsection{Re-interpreting Bayesian probabilities}

Recently, McKay (2012) has challenged the claim that the selection of hypothesis $\left(\mathrm{H}_{\mathrm{s}}\right)$ is based on a normative Bayesian model and therefore the product of a rational abductive inference. Instead, and in accordance with Aimola Davies and Davies (2009), he proposes a further cognitive deficit-a bias towards explanatory adequacy-which results in the patient favouring the hypothesis that best explains the perceptual data (abnormal data O) irrespective of its low prior probability.

To explain: recall how, when presenting the prior probabilities of the competing hypotheses available to explain abnormal data O (see Section 2), Coltheart et al. estimated $\left(\mathrm{H}_{\mathrm{w}}\right)$ at 99:100 and $\left(\mathrm{H}_{\mathrm{s}}\right)$ as 1:100. McKay $(2012)$ considers $\left(\mathrm{H}_{\mathrm{s}}\right)$ to be "a fantastically unlikely occurrence" (p. 340), and therefore the ratio of $1: 100$ to be somewhat unrealistic. Instead, he suggests a ratio of 1:3650. When the prior probability of $\left(\mathrm{H}_{\mathrm{s}}\right)$ is set at this more realistic (although, by his own admission, still quite generous) level, McKay argues that one could not reasonably expect $\left(\mathrm{H}_{\mathrm{s}}\right)$ to be selected as the most suitable hypothesis.

Here, then, lies the problem with inserting what are effectively unsubstantiated values into Bayes' theorem: different outcomes are produced relative to the values one computes, and there is no way of knowing what these values should be. The inclusion of estimated values is, of course, intended for illustrative purposes, rather than as a proof. Nevertheless, it does highlight a key difference in the approaches of Coltheart et al. and McKay. Given the probabilities proffered by McKay, one could not rationally arrive at the stranger hypothesis $\left(\mathrm{H}_{\mathrm{s}}\right)$ as the best explanation of abnormal data O. Consequently, the selection of hypothesis $\left(\mathrm{H}_{\mathrm{s}}\right)$ could not be the result of normal reasoning, as Coltheart et al. would have us believe, and so the patient must be biased against the normative Bayesian model. The implication of this, for McKay, is that a further pathology is required to explain the selection of the stranger hypothesis: namely, a bias towards explanatory adequacy. This means that the patient's subperson processing is biased in favour of the ex- 
planatory prowess of the stranger hypothesis irrespective of its low prior probability value.

McKay and Coltheart et al. disagree over the extent to which the abductive inference employed by the patient falls within the parameters of normal reasoning. What they have in common is the view that the perceptual state the hypothesis is trying to explain is not something the patient is conscious of. In both cases, the first delusion-related event to enter consciousness is the belief "This person is not my wife...". In the next section, I present a problem with this view. Throughout, I will focus on Coltheart et al.'s model, although it should be understood that the criticism is equally applicable to McKay.

3.2 Problems with the claim that the belief is the first conscious delusionrelated event

According to the example used by Coltheart et al., prior to the neuropsychological disconnection (which they attribute to a stroke) — call it $t_{1}$ - the Capgras husband's face processing system is working normally and so conforms to the normative requirements of $\left(\mathrm{O}_{n w}\right)$ when in the presence of his wife, and $\left(\mathrm{O}_{n s}\right)$ when in the presence of strangers. At $t_{2}$, however-after the disconnectionwhen the husband is in the presence of his wife, data $\mathrm{O}$ no longer conforms to the requirements of $\left(\mathrm{O}_{\mathrm{nw}}\right)$. Following Coltheart et al.'s model, at time $\mathrm{t}_{1}$, and at the conscious level, when the husband sees his wife presumably he is aware of the fact that the person in front of him is his wife. Forming part of his conscious set of background beliefs (inter alia) is the belief corresponding somewhat unremarkably to "This is my wife". At $t_{2}$, however, all remains the same within the patient's experience except that the belief which now enters consciousness and forms part of his background beliefs has changed from "This is my wife" to "This is not my wife", and no doubt stands out because of this. Certainly it would be inconsistent with the belief that she looks just like her or sounds like her, acts like her, is wearing her clothes, claims to be her (etc). Of course, the extended belief "This is not my wife but an impostor" would be consistent with these other beliefs. Nevertheless, it would still result in a sudden (and dare I say it, inexplicable) switch from "This is my wife" at $t_{1}$ to "This is not my wife but an impostor" at $\mathrm{t}_{2}$, given that all else remains the same.

Importantly, then, if all else remains the same from $t_{1}$ to $t_{2}$ (recall that, for Coltheart et al., the first delusion-relevant event of which the patient is aware is the belief "This is not my wife...") it is difficult to understand how the sudden emergence of the impostor belief at $t_{2}$ could be experienced as anything other than an unbidden thought (Young 2011b). The Capgras husband's wife physically appears to him in the normal way, is recognized by the FRU and PINs in the normal way, thereby producing a normal visual percept of his wife (consciously experienced as such, at least in terms of her physical features), 
but suddenly the belief "This is not my wife..." 'pops' into his head. Abductive inference provides an explanation of how the best candidate hypothesis is selected given abnormal data $\mathrm{O}$ (whether based on a normative or biased Bayesian model). What is not made clear, however, is what is involved in accepting and therefore transforming a hypothesis into a belief below the level of consciousness, or how this subpersonal selection and acceptance relates to any conscious endorsement of the belief, including coming to understand why I (qua the Capgras husband) suddenly believe my wife is an impostor, rather than that I am simply experiencing a recurring unbidden thought with content "This is not my wife but an impostor".

Given that there is a conscious-subconscious (or personal-subpersonal) divide within Coltheart et al.'s account, how is the sudden presentation of the delusional belief, at the conscious level, to be understood by the patient at this same conscious level? If the husband is unaware of reduced autonomic arousal when in the presence of his wife (which Coltheart et al. hold to be the case)-which forms part of the evidence used at the subpersonal level to determine that something is different with the percept and therefore that there is a discrepancy in need of explanation (abnormal data O)-then what is he to make of this sudden change of belief relative to his other background beliefs when it emerges seemingly fully endorsed into consciousness? Experientially, is there a sense of conviction which accompanies the sudden emergence of the impostor belief? If so, what causes this? If not, to reiterate, would the sudden appearance of the belief, with its unprecedented content (from the patient's perspective) not be treated as an unbidden thought?

\section{Introducing a sense of conviction}

According to Turner and Coltheart (2010), prior to their emergence into consciousness, thoughts are evaluated courtesy of an unconscious checking system. Thoughts that require extra checking are 'tagged' and are picked up by the conscious checking system for further evaluation before being accepted or rejected (depending on the outcome of this second-level evaluation). Thoughts that are tagged subpersonally are "accompanied by the normal experience of doubt” (2010: 355). In the case of patients suffering from delusions (including the Capgras delusion), however, "this unconscious checking system fails, resulting in an absence of doubt which [Turner and Coltheart argue] confers an inappropriate feeling of conviction” (ibid.).

In the case of a non-deluded husband, should the thought "This is not my wife...” suddenly pop into his conscious awareness, then if it has been tagged correctly at the subpersonal level, it should be accompanied by doubt and likely be rejected after further conscious evaluation. In the case of the Capgras husband, in contrast, the proposition "This is not my wife..." is not tagged and 
so is not accompanied by doubt; rather, the thought enters consciousness with an accompanying sense of conviction: the sort of conviction one typically associates with something one believes.

An accompanying sense of conviction could certainly be used to distinguish between delusional and unbidden thoughts. One could therefore argue that the patient does not experience the sudden emergence into consciousness (at $\mathrm{t}_{2}$ ) of the thought "This is not my wife..." as unbidden because of the sense of conviction which allegedly accompanies it. Such a possibility does of course raise the issue of whether subpersonal tagging is in fact faulty in the case of the Capgras patient, as Turner and Coltheart suggest, or simply not used, given that Coltheart et al. posit that hypothesis $\left(\mathrm{H}_{\mathrm{s}}\right)$ was selected using normal reasoning. If the hypothesis was selected using normal reasoning then what would an unconscious checking system be checking the hypothesis against? It would seem that there is no reason to refer to faulty tagging in the case of Coltheart et al.'s approach because such a tag should not accompany the thought (the stranger hypothesis) if it was arrived at through normal reasoning. In the case of McKay's explanation, however, given his need for a secondstage cognitive bias (at the subpersonal level), reference to a faulty tagging system might help differentiate delusional from unbidden thought; although I accept that this is merely speculation.

\subsection{Why a sense of conviction is not enough}

Despite questions over precisely how it occurs, particularly within Coltheart et al.'s account of normal reasoning, I nevertheless concede that the salience of an accompanying sense of conviction would make the patient feel that the content of the thought reliably indicates some truth about the state of the world: in this case that this woman is not who she claims to be. This, I accept is compatible with the role of a belief which is to represent the world as being a certain way. I also concede that a sense of conviction helps differentiate the thought from something that one might otherwise experience as unbidden. Nevertheless, I still feel more work needs to be done to explain the move from subpersonal hypothesis selection to fully-fledged (delusional) belief formation. A sense of conviction may form part of this explanation but it is not sufficient. To illustrate why not, consider the following example, presented by Davies and Egan (2013) (although originally taken from Chatterjee \& Mennemeier, 1996: 227), of a patient (HS) who, although recovered from anosognosia (the inability to recognize one's disability), still felt that the idea the he could move his paralysed limb was credible even though it was not something he actually continued to believe. 
E: What was the consequence of the stroke?

HS: The left hand here is dead and the left leg was pretty much.

HS: (later): I still feel as if when I am in a room and I have to get up and go walking... I just feel like I should be able to.

E: You have a belief that you could actually do that?

HS: I do not have a belief, just the exact opposite. I just have the feeling that sometimes I feel like I can get up and do something and I have to tell myself 'no I can't'.

HS does not believe that he can "get up and do something"; yet he feels that the idea is credible. What does he mean when he states that he feels like he can get up and go walking? Likewise, what is it to have an idea (even a credible idea) that this can be done? Might this be reference to a sense of conviction which accompanies the thought? Possibly; possibly not. In truth, it is unclear. What is clear is that HS does not believe he can "get up and do something”. If he does not believe this then what is it that he rejects? Must HS have an initial and fleeting belief that he can do these things which he then rejects? To reiterate, he does not believe that it is a belief he is rejecting. Moreover, is the following even coherent: "I believe $x$ but I do not believe that I believe it and so reject it"? " Whatever label we attach to the mental state with content "you can get up and do something", and whatever the cause of this mental content, it is not consciously endorsed by HS; hence its rejection.

HS does not believe he is rejecting a belief, only a credible idea. Consider, then, the following extract taken from Turner \& Coltheart (2010: 371) of a Capgras patient in the early stages of recovery:

Examiner: What has made you realise that they're just imaginations? People telling you that?

Patient: No it's just myself that's done it. I've started going through it, and seeing what could possibly happen and what couldn't happen. That was wrong, that couldn't happen. Even though it has happened it couldn't. Mary couldn't suddenly disappear from the room, so there must be an explanation for it. So then I try and workout what...

She [the imposter] knows me way back. The lady knows me way back. She could say things that happened 40 years ago, and I wonder where she gets them from. And then I worked it out and I've wondered if it's Mary all the time. It's nobody else.

\footnotetext{
${ }^{9}$ Currie (2000) in fact draws a distinction between a first-order belief (that $p$ ) and higher-order belief (believing that $p$ ) in his account of delusions.
} 
Turner and Coltheart theorize that during the acute stage of the patient's disorder, both his unconscious and conscious checking systems were impaired. Thus, he formed the delusional belief which entered consciousness accompanied by a sense of conviction (lack of doubt) and so presumably was not checked by the conscious checking system (there was no reason to check it given that it was not tagged). However, the conscious checking system can be triggered by external factors (such as friends/relatives saying that the alleged impostor is really who they claim to be); but, initially, this too was faulty, so there was no rejection of the belief. What has changed, according to Turner and Coltheart, is that the conscious checking system now appears to be working which is why the patient now believes that the person is and always was Mary. Yet Turner and Coltheart claim (correctly, I would say) that the first factor impairment (the occurrence of abnormal data 0 ) is still producing the thought (as they refer to it, not belief) that the woman in the house is not his wife, which the patient is able to challenge owing to his now correctly functioning conscious evaluative system.

Let us consider the changes to this patient in a more structured way. At $t_{1}$ (prior to the disorder) the patient believes Mary is his wife. At $t_{2}$ (with the onset of the disorder), abnormal data $\mathrm{O}$ is produced when Mary is present. Hypothesis $\left(\mathrm{H}_{\mathrm{s}}\right)$ is selected as the best explanation for this and the belief "This is not my wife..." enters consciousness accompanied by a sense of conviction. This belief is not consciously evaluated and rejected, owing to problems with the conscious checking system. At $t_{3}$ (at which point the conscious checking system is functioning again), the patient is able to challenge the thought "This is not my wife...”.

It is not unreasonable to allow that after some re-evaluation the patient could reject the belief "This person is not my wife...”. I also concur with Turner and Coltheart that, owing to continued neurological impairment, abnormal data $\mathrm{O}$ would still be produced and still need to be explained. If the thought "This is not my wife...” is still entering consciousness then this must mean that the stranger hypothesis is still being selected. The consequence of this is that it needs to be challenged by the recovering patient and so rejected continually. If one holds that hypothesis $\left(\mathrm{H}_{\mathrm{s}}\right)$ enters consciousness as a belief, then we have a situation at $\mathrm{t}_{3}$ similar to that discussed in the context of patient HS whereby the Capgras patient believes $x$ and yet does not believe that he believes $x$. This conflict is removed, of course, if, at $t_{3}$, the patient is merely aware of the thought $x$ (perhaps even of the thought feeling credible) and yet does not believe $x$. What is not clear from Coltheart et al.'s model, and the argument of Turner and Coltheart, is how we arrive at a mere thought at $t_{3}$ given that (a) we had a belief at $t_{2}$ and (b) the mechanism which brought about the belief at $\mathrm{t}_{2}$ has not changed. 


\section{Building a case for the explanatory role of patient experience}

One way to resolve this problem is to hold that when the stranger hypothesis enters consciousness at $t_{2}$ it is not yet held as a belief but merely acknowledged, even entertained, as a thought. Further explanation is required detailing how this thought is then given sufficient credence to be transformed into a belief. It is towards such an explanation that I now turn; one that reinstates an explanatory role for patient experience within Coltheart et al.'s revisionist model.

\subsection{Anomalous experience in the absence of delusional belief}

Turner and Coltheart provide an example of what they refer to as first factor neuropsychological impairment in the absence of conscious or unconscious checking impairments. Below is an extract taken from a patient who had undergone temporal lobe surgery as a treatment for epilepsy (adapted from Turner \& Coltheart 2010: 371-72):

Interviewer: After the operation, did you notice any change?

Patient: Yes, the first thing I noticed was Mum, when she walked in the room, it was just a... it was cardboard... an image, if that's the right word... it was like a picture of her, but it wasn't her... it's hard to, I can't sort of explain it 'cause it... inside... it's hard.

Interviewer: Right. It looked like a real person, did it?

Patient: Oh, yeah. There's Mum walking in the room.

Interviewer: Right. So you knew it looked like your Mum, but...

[Section omitted from original]

Patient: She... I don't know... so you can look different by expression or... just through feeling, you can look different by, you know, doing your hair or whatever, but it wasn't different in that way, it was of having the different inside of her, I can't sort of explain it...

[Section omitted from original]

Patient: Just didn’t feel like her.

Interviewer: How did that feel to you?

Patient: Scary.... Has their lifestyle changed? Have I changed? Have they changed in a funny sort of way? I don't know. It's weird and it gets confusing. 
Given that this patient is said to have a first factor neuropsychological impairment, and given that it is claimed by Turner and Coltheart that what prevents her from developing "a Capgras-like delusion” (2010: 371) is intact conscious and unconscious checking systems not, it would seem, a different firstfactor neuropsychological impairment, it seems reasonable to conclude from this that these authors are suggesting that the patient has the same abnormal data $\mathrm{O}$ (in need of explanation) as the Capgras patient. What is also suggested is that the intact unconscious checking system prevents the stranger hypothesis from entering consciousness as a belief; rather it "enables [the patient] to describe the thought in 'as if' terms..." (ibid.). This, again, raises the question of why the unconscious checking system would tag the stranger hypothesis (thus preventing it from becoming a belief in the absence of further evaluation and confirmation) given that it is arrived at, according to Coltheart et al. using abductive inference within the parameters of normal reasoning. That issue aside: what this example does illustrate is that in conjunction with the neuropsychological impairment (suggestive of abnormal data 0 ) the patient has an anomalous experience when in the presence of her mother. As she states: It just does not feel like her.

If one is arguing that the patient above and the Capgras patient share the same underlying neuropsychological impairment, and that the only reason Capgras-like symptoms are not presented in the patient treated for epilepsy is the intact conscious and unconscious checking systems, then it seems reasonable to surmise that whatever is producing the feeling that this is not the patient's mother would also produce a corresponding feeling (mutatis mutandis) in the Capgras husband in relation to his wife. The non-deluded patient does not hold the belief "This is not my mother...", but apparently has 'as if' thoughts to that effect? Now, it may be that the 'as-if' thoughts are not accompanied by a sense of conviction. If so, then what prevents them from being experienced as unbidden? The patient does not experience the thoughts as unbidden because these thoughts are accompanied by an anomalous experience. The stranger hypothesis (courtesy of trying to explain abnormal data $\mathrm{O}$ at the subpersonal level) enters consciousness as the thought "This is not my mother..." (or some such thing) and is not treated as unbidden because it is accompanied by the anomalous experience. Given what the patient is experiencing, the thoughts have a context: for what sense could she make of such 'as if thoughts unless they are accompanied by some form of anomalous experience?

\subsection{What the accompanying anomalous experience adds to the explanation}

When comparing the non-deluded patient with a Capgras patient, given the suggested similarity between the two in terms of abnormal data $\mathrm{O}$, it is not clear why this patient would have an accompanying anomalous experience 
and the Capgras patient would not. Moreover, if in both cases abductive inference selects the stranger hypothesis as the best explanation which allegedly enters consciousness as an 'impostor' belief then, in the case of the nondeluded patient, the following would entail (as commented on before): I believe $x$ but do not believe that I believe $x$. If it is suggested that, in the case of the non-deluded patient, the unconscious checking mechanism prevents the hypothesis from being accepted as a belief when entering consciousness then it needs to be explained how this system is able to tag a thought that is arrived at using a process that is deemed by Coltheart et al. to be rational, and indeed why it would want to do this.

Instead, it is my contention that the occurrence in consciousness of the thought (not the belief) "This is not my mother..." (or something similar), alongside a salient difference in the patient's experience when in the presence of her mother, not only makes her feel uneasy (it was scary for her) but makes her question the situation. As she states: 'Has their lifestyle changed? Have I changed? Have they changed in a funny sort of way? I don't know. It's weird and it gets confusing'. The anomalous experience puts the thought into context and may even give it some credence (as with HS, the thought-or ideamay feel credible), but this is not enough for the thought to achieve the status of a belief (again, as was the case with HS): for the patient does not believe that the thought "This is not my mother..." represents some truth about the world. In short, she does not believe it.

What role is this thought playing if it is not a belief? To address this question, consider the work of Bayne and Pacherie (2005). These authors, while discussing Currie and Ravenscroft's (2002) distinction between imagination and belief, present different forms of imagination in propositional form, of which indicative imagination - which they assert is easily triggered by perception-is of interest. To imagine $\mathrm{P}$ in the guise of indicative imagination, Bayne and Pacherie inform us, "is to have some inclination-however slight-to think that $P$ is the case” (2005: 167). In fact:

Indicative imagination and belief seem to be on a continuum, insofar as both are attitudes to the way the world actually is (ibid.)... To imagine $\mathrm{P}$ in the indicative sense is to think that $\mathrm{P}$ might actually be true, it is to take $\mathrm{P}$ as a contender for the truth. (ibid. 170)

The subpersonal selection of the best candidate hypothesis, as proposed by Coltheart et al.-based as it is on perceptual information indicating some state of the world (the authenticity of the husband's wife)-seems compatible with the belief-like proposition referred to by Bayne and Pacherie as indicative imagination. After all, the very nature of abductive inference is that it should select, as a contender for the truth, the 'best fit' hypothesis from those available, irrespective of whether this results in a claim to the truth of $\mathrm{P}$ or, more relevant to the Capgras delusion, the truth of $\left(\mathrm{H}_{\mathrm{s}}\right)$ (Coltheart, Langdon 
\& McKay 2011). The 'belief' which permeates consciousness should therefore be likened to an example of indicative imagination. In effect, the non-deluded patient or even the Capgras husband, at this stage, is entertaining the possibility that the woman who looks like his wife is an impostor (this proposition has been selected as a contender for the truth).

In the case of the Capgras delusion, it is my contention that the stranger hypothesis $\left(\mathrm{H}_{\mathrm{s}}\right)$ enters consciousness as a thought whose function is captured by Bayne and Pacherie's indicative imagination. It is also my contention that this thought is provided a context in virtue of the co-occurrence of an anomalous experience. If the thought is also accompanied by a sense of conviction then this too will be more meaningful if present in conjunction with an anomalous experience. The patient may reflect: "It makes sense that this thought is credible given what I am experiencing” (again, much as I have argued in the case of HS and the patient who was treated for epilepsy). How the Capgras and nondeluded patients differ is, in accordance with Turner and Coltheart (2010), down to a difference in their conscious checking or belief evaluation system (Coltheart 2007).

\section{Putting it all together}

Given the occurrence of the anomalous experience alongside the thought "This person is an impostor" (or something similar), perhaps even with an accompanying sense of conviction, the patient elevates the thought (qua indicative imagining) to the status of a belief because the thought (now a belief) helps explain the patient's strange experience by giving it meaning. The anomalous nature of the Capgras patient's experience can be likened to a sense of unfamiliarity in the form of estrangement (Young 2007, 2008b, 2009, 2010). The patient's acceptance of the impostor belief should be understood in terms of the role it plays in explaining why there is a change in the patient's experience-the feeling of estrangement-when in the presence of his (putative) wife. Importantly, the now accepted belief shapes the nature of the experiential content such that belief and experience become congruent (Young 2008a; 2011a). To explain: when the belief is formed, the patient no longer experiences a feeling of estrangement towards the putative wife because what he now perceives (shaped as it is by the belief) is an impostor. Given that he believes he is looking at an impostor, what was once a sense of unfamiliarity in the form of estrangement-the anomalous experience-is now transformed into an experience of how one should feel when in the presence of a stranger. What the patient feels now accords with the normative state of familiarity associated with strangers: namely, a lack of familiarity. 
Breaking down what enters consciousness into stages, we get:

(a) The co-occurrence of anomalous experience (feeling of unfamiliarity as estrangement) and the thought (qua indicative imagining): "This person is not my wife, she is an impostor”.

(b) The anomalous experience gives meaning to the thought (qua indicative imagining). It makes sense that I should be thinking this given what I am feeling.

(c) The thought (qua indicative imagining) is accepted as a belief (change of epistemic status) because it helps explain the experience (compatible with the explanationist account). In turn, the newly acquired belief helps shape the husband's perception of his putative impostor wife. Given that the husband now believes she is an impostor, an imposter is what he perceives (sees). Importantly, this is also compatible with the endorsement account because the belief, in addition to explaining the initial anomalous experience and helping transform the experience, now acts to endorse what the husband experiences: he perceives an impostor wife and seeing is further evidence for believing.

(d) The anomalous feeling that was once interpreted as a feeling of unfamiliarity in the form of estrangement is now transformed into a normative feeling of familiarity regarding the impostor: namely, a lack of familiarity. This is how I should feel when in the presence of a stranger.

(e) The belief and the experience are now congruent and locked in a cycle of mutual effect. Given what I believe, it makes sense that this is how I feel.

The (delusional) belief serves a dual function. Not only does it provide a means of interpreting the experience-of accounting for its anomalousness (thereby serving an explanationist function)_it also instils meaning. The patient looks to the belief, "That woman is not my wife, she is an impostor" to give some semblance of meaning to his sense of estrangement. Forming and accepting this belief then structures what he see when he looks at the woman: namely, an impostor (thereby serving an endorsement function). In terms of explaining the belief's resistance to revision: Why would he look to revise such a match up? From the patient's perspective, the validity of the belief and the authenticity of the experience are inextricably linked insofar as the congruence between belief and experience provides strong (personal) evidence for the validity of the former and the authenticity of the latter.

In relation to this last point, Leeser and O'Donohue (1999) argue that delusional beliefs are resistant to revision because their content is unfalsifiable, particularly from the first-person perspective (see also Davies et al., 2001). How does one refute the claim that someone is an impostor? After all, modern or alien technology (“That we don't yet know about")—even magic or the dark 
arts-may be capable of such physical duplication, even of DNA (Broome 2004). Everyone else may be fooled, including family and friends, but not the subject of the delusion. The fact that it may be difficult to refute the delusional belief because of the nature of its content may add to the reasons why the belief is maintained; but, for the Capgras patient, perhaps it is enough that the delusional belief authenticates the experience in a manner that no alternative proposition can.

\section{Concluding remarks}

The aim of this paper has been to reinstate a role for patient experience in light of Coltheart et al.'s revisionist model which renders such experience redundant. While I find much within Coltheart et al.'s approach instructive, I nevertheless consider there to be problems with the model as its stands; having said that, I do not advocate abandoning the model altogether. Others (McKay 2012; see also Davies \& Egan 2013) have provided detailed critical discussion on the Bayesian approach adopted by Coltheart et al.; asking whether the Capgras patient adheres to a normative or biased Bayesian model. I have chosen instead to address problems with the notion that (a) a belief enters consciousness, rather than merely a thought, and (b) that this belief constitutes the first delusion-related event of which the patient is conscious. What I hope to have shown is that there is more explanatory worth in positing the co-occurrence of thought and anomalous experience prior to the formation of the delusional belief. Such a position is compatible with both abnormal data $\mathrm{O}$ and the use of abductive inference.

As a final point, given that I have not discussed how it is that the delusional belief, once formed, is maintained, what is left unclear is how many factors are involved in the formation and maintenance of the delusion. Davies and Egan (2013) have pointed out that Coltheart et al. require only one factor (or deficit) prior to the belief formation and a second to account for its maintenance (a deficit in belief evaluation). McKay, on the other hand, posits two deficits prior to belief formation. Davies and Egan then speculate over the extent to which this account requires a further factor to account for the belief's maintenance. I am agnostic when it comes to whether the Bayesian model is biased (McKay) or unbiased (Coltheart et al.), and so whether one or two deficits are required prior to belief formation (I concur that a deficit in the face recognition system forms the neurological basis for the disorder). All I insist on is that the (delusional) belief formation is the product of a deficit in the patient's conscious belief evaluation system (Coltheart 2007), and that for this to result in the formation of the delusional belief, two delusion-related events must co-occur in consciousness: the impostor thought and the anomalous experience. 


\section{References}

Aimola Davies, A. M., and Davies, M. 2009. Explaining pathologies of belief. M. R. Broome and Bortolotti, L., eds. Psychiatry as Cognitive Neuroscience: Philosophical Perspectives. Oxford: Oxford University Press: 285-323.

Bauer, R.M. 1984. Autonomic Recognition of Names and Faces in Propopsgnosia: A Neuropsychological Application of the Guilty Knowledge Test. Neuropsychologia, 22: 457-469.

Bayne, T., and Pacherie, E. 2004. Bottom-Up or Top-Down: Campbell's rationalist account of monothematic delusions. Philosophy, Psychiatry and Psychology, 11(1): 111.

Bayne, T., and Pacherie, E. 2005. In Defence of the Doxastic Conception of Delusions. Mind and Language, 22(2): 163-188.

Bortolotti, L. 2005. Delusions and the Background of Rationality. Mind and Language, 20(2): 189-208.

Breen, N., Caine, D., and Coltheart, M. 2000. Models of Face Recognition and Delusional Misidentification: A Critical Review. Cognitive Neuropsychology, 17(1/2/3): 55-71.

Brighetti, G. Bonifacci, P., Borlimi, R., and Ottaviani, C. 2007. Far from the heart far from the eye: evidence from the Capgras delusion. Cognitive Neuropsychiatry, 12(3): 189-197.

Broome, M. R. 2004. The Rationality of Psychosis and Understanding the Deluded. Philosophy, Psychiatry, and Psychology, 11(1): 35-41.

Capgras, J., and Reboul-Lachaux, J. 1923. L'illusion des 'soises' dans un délire systématisé chronique. Bulletin de la Société Clinique de Médicine Mentale, 11: 6-16.

Chatterjee, A., and Mennemeier, M. 1996. Anosognosia for hemiplegia: Patient retrospections. Cognitive Neuropsychiatry, 1: 221-37.

Coltheart, M. 2007. The $33^{\text {rd }}$ Sir Fredrick Bartlett Lecture. Cognitive neuropsychiatry and delusional belief. The Quarterly Journal of Experimental Psychology, 60(8): 1041-1062.

Coltheart, M., Langdon, R., and McKay, R. 2011. Delusional belief. Annual Review of Psychology, 62: 271-98.

Coltheart, M. Menzies, P., and Sutton, J. 2010. Abductive inference and delusional belief. Cognitive Neuropsychiatry, 15(1): 261-287.

Currie, G. 2000. Imagination, hallucination and delusion. Mind and Language, 15(1): 168-83.

Currie, G., and Ravenscroft, I. 2002. Recreative Minds. Oxford: Oxford University Press.

Davies, M., and Coltheart, M. 2000. Introduction: Pathologies of Belief. Mind and Language, 15(1): 1-46.

Davies, M., Coltheart, M., Langdon, R., and Breen, N. 2001. Monothematic delusions: Towards a two factor account. Philosophy, Psychiatry, and Psychology, 8(2/3): 133158. 
Davies, M., and Egan, A. 2013. Delusion: Cognitive approaches Bayesian inference and compartmentalisation. Fulford, K.W.M., Davies, M., Gipps, R.G.T., Graham, G., Sadler, J., Stanghellini, G., and Thornton, T., eds. The Oxford Handbook of Philosophy and Psychiatry. Oxford: Oxford University Press.

Ellis, H.D., and Lewis, L. 2001. Capgras Delusion: A window on face recognition. Trends in Cognitive Science, 5(4): 149-156.

Ellis, H.D., and Young, A.W. 1990. Accounting for Delusional Misidentification. British Journal of Psychiatry, 157: 239-248

Ellis, H.D., and Young, A.W., Quayle, A.H. and de Pauw, K.W. 1997. Reduced autonomic responses to faces in Capgras delusion. Proceedings of the Royal Society: Biological Science, B264: 1085-1092.

Frazer, S.J., Roberts, J. M. 1994. Three cases of Capgras' syndrome. British Journal of Psychiatry, 164: 557-559.

Gerrans, P. 2000. Refining the explanation of Cotard's delusion. Mind and Language, 15(1): 111-122.

Gerrans, P. 2002. A one-stage explanation of the Cotard delusion. Philosophy, Psychiatry, and Psychology, 9(1): 47-53.

Gilleen, J., and David, A.S. 2005. The cognitive neuropsychiatry of delusions: from psychpathology to neuropsychology and back again. Psychological Medicine, 35: 512.

Haxby, J.V., Gobbini, M.I., Furey, M.L., Ishai, A., Schouten, J.L., and Pietrini, P. 2001. Distributed and Overlapping Representations of Faces and Objects in Ventral Temporal Cortex. Science, 293: 2425-2430.

Haxby, J.V., Hoffman, E.A., and Gobbini, M.I. 2000. The distributed human neural system for face perception. Trends in Cognitive Science, 4(6): 223-233.

Hirstein, W., and Ramachandran, V.S. 1997. Capgras' Syndrome: A Novel Probe for Understanding the Neural Representation of the Identity of Familiarity of Persons. Proceedings of the Royal Society: Biological Sciences, B246: 437-444.

James, W. 1950. Principles of psychology Vol. 2. New York: Henry Holt and Co. Original work published 1890.

Klee, R. 2004. Why Some Delusions are Necessarily Inexplicable Beliefs. Philosophy, Psychiatry, and Psychology, 11(1): 25-34.

Leeser, J., and O'Donohue, W. 1999. What is a delusion? Epistemological dimensions. Journal of Abnormal Psychology, 108(4): 687-694.

Maher, B.A. 1974. Delusional Thinking and Perceptual Disorder. Journal of Individual Psychology, 30: 98-113.

Maher, B. A. 1988. Anomalous experience and delusional thinking: The logic of explanations. Oltmanns, T. F., and Maher., B. A., eds. Delusional beliefs. New York: Wiley: 15-33. 
Maher, B. A. 1999. Anomalous experience in everyday life: Its significance for psychopathology. The Monist, 82(4): 547-570.

McKay, R. 2012. Delusional Inference. Mind and Language, 273: 330-355.

Pacherie, E. 2009. Perception, Emotion, and Delusions: The Case of the Capgras Delusion. Bayne, T., and Fernández, J., eds. Delusion and Self-Deception: Affective and Motivational Influences on Belief Formation. New York: Psychology Press: 107-125.

Schweinberger, S.R., and Burton, MA. 2003. Covert recognition and the neural system for face processing. Cortex, 39: 9-30.

Stone, T., and Young, A.W. 1997. Delusions and Brain Injury: The Philosophy and Psychology of Belief. Mind and Language, 12(3/4): 327-364.

Turner, M., and Coltheart, M. 2010. Confabulation and delusion: A common monitoring framework. Cognitive Neuropsychiatry, 15: 346-76.

Young, A.W. 1999. Delusions. The Monist, 82(4), 571-589.

Young, A.W., and de Pauw, K.W. 2002. One Stage is Not Enough. Philosophy, Psychiatry, and Psychology, 9(1): 55-59.

Young, G. 2007. Clarifying 'Familiarity’: Phenomenal experiences in prosopagnosia and the Capgras delusion. Philosophy, Psychiatry and Psychology, 14(1): 29-37.

Young, G. 2008a. Capgras Delusion: An interactionist model. Consciousness and Cognition, 17(3): 863-876.

Young, G. 2008b. Restating the role of phenomenal experience in the formation and maintenance of the Capgras delusion. Phenomenology and the Cognitive Sciences, 7(2): 177-189.

Young, G. 2009. In what sense 'familiar'? Examining experiential differences within pathologies of facial recognition. Consciousness and Cognition, 18(3): 628-638.

Young, G. 2010. Delusional Misidentification. New York: Nova Science Publishers, Inc.

Young, G. 2011a Beliefs, experiences and misplaced being: An interactionist account of delusional misidentification. Phenomenology and the Cognitive Sciences, 10(2): 195215.

Young, G. 2011b. On Abductive Inference and Delusional Belief: Why there is still a role for patient experience within explanations of Capgras delusion. Cognitive Neuropsychiatry, 16(4): 303-325. 